\title{
Теоретические основы медиаисследований: процесс развития и результаты
}

(рецензия на книгу: Вартанова Е.Л. Теория медиа: отечественный дискурс. М.: Фак. журн. МГУ; Изд-во Моск. ун-та, 2019)

Наталия Урина

(c) Урина Наталия Валентиновна доктор филологических наук, старший научный сотрудник кафедры зарубежной журналистики и литературы факультета журналимстики МГУ имени М.В.Ломоносова (г.Москва, Россия), natalia_urina@mail.ru
Медийная составляющая современного мира растет и видоизменяется, воздействуя на все сферы жизни. Сложные процессы, связанные с медиа, требуют их глубокого и всестороннего изучения. Для этого нужны новые или адекватно модернизированные концепции и теории сегодняшнего дня. При этом подразумевается осмысление теоретической мысли прошлого, изучение и оценка современного развития теорий и создание теоретической базы для будущих медиаисследований. В этом контексте особое внимание привлекает монография профессора Е.Л.Вартановой «Теория медиа: отечественный дискурс». Предваряет исследование убедительная аргументация не только актуальности темы, но и трудностей ее разработки как на теоретическом, так и на практическом уровне. Однако важна не только актуальность темы, но и подходы к решению проблем, поскольку выявление теории ведется на волне отечественного научного дискурса. Эта монография - результат целенаправленной работы автора, отраженной в книгах и статьях, в лекциях и докладах.

Следует отметить и то, что под научным руководством профессора Е.Л. Вартановой 
и при ее активном участии были осуществлены значимые научные исследования медийной сферы и увидели свет многие коллективные монографии. Так, интенсивная и скоординированная работа руководимого ею научного коллектива (М.Е. Аникина, А.В. Вырковский, А.Н. Гуреева, Д.В. Дунас, М.И. Макеенко, С.С. Смирнов) в рамках проекта «Разработка фундаментальных основ отечественной теории медиа в условиях трансформации общественных практик и цифровизации СМИ» дала ощутимые плоды в виде трех коллективных монографий и словаря. Каждая из этих книг «Трансформация отечественной теории медиа: состояние и тенденции развития» (2017), «Фундаментальные основы теории медиа в контексте общественного развития: опыт разработки» (2019), «От теории журналистики к теории медиа. Динамика медиаисследований в современной России» (2019) - имеет свою бесспорную научную значимость и заслуживает отдельного рассмотрения. Важно и то, что в каждой из них в той или иной мере присутствовал теоретический аспект и как предмет исследования, и как базовая часть медиаисследований, проводившихся научным коллективом.

Особенно важным представляется разработка тезауруса - «Отечественная теория медиа: основные понятия. Словарь» (2019), содержащего 100 понятий, актуальных для отечественной теории медиа. Изучение медийной практики и разработка концепций требуют прежде всего приведения в порядок понятийного аппарата. В научной литературе, документах, журналистском или политическом лексиконе существует множество толкований и употреблений различных понятий. Соответствие понятия и феномена, его вызвавшего, - один из наиболее актуальных вопросов в гуманитарных науках. В отдельных случаях, правда, не столь важна точность первого, сколько само отражение явления. В целом, осмысле- ние каждого понятия, его возникновения и эволюции - это путь к пониманию самого феномена. Следует еще раз подчеркнуть, что, к сожалению, в теоретических трудах и эмпирических исследованиях все еще прослеживается тенденция к расширению и усложнению понятийного аппарата, а не кего упорядочению и уточнению. Отчасти это вызвано широким введением в научный оборот работ, принадлежащих перу ученых различных стран, что само по себе является моментом весьма положительным, но требующим от переводчиков более глубокого знания материи и уже существующих традиционных форм перевода. А в результате порой под новым словом в науке подразумевается не новая мысль, а новое обозначение уже известного явления. Представленный словарь в определенной мере поможет разобраться в существующем лексическом многообразии и преодолеть широкую вариативность смыслов. Показательно, что в главе литеры «М», содержащей 32 понятия, 27 начинаются с лексемы «медиа» (от «медиаактивизма» до «медиаэффектов»), а это свидетельствует о доминирующей роли медиа в понятийном аппарате исследователей.

Названные выше научно значимые работы логично объединяет труд Е.Л.Вартановой, в котором обобщены как ее ранее появившиеся теоретические разработки, так и полученные в ходе реализации проекта. Рассмотрение медиаисследований как области знаний, как научной дисциплины и как отдельного направления в образовании потребовало от автора определения их объектно-предметного поля. Его формируют такие предметные области, как журналистика, СМИ, массовая коммуникация, медиакоммуникация, медиа, изучение которых актуализируется в последние годы. Поскольку медиа рассматриваются как широкое понятие, интегрирующее «коммуникационные каналы, содержание технологически опосредованной комму- 
никации и их эффекты» (с. 5)2, то именно это позволяет выявить границы, природу и особенности медиаисследований. Учитывая эти и другие факторы, представляется обоснованной концентрация внимания автора на двух аспектах вопроса, которым посвящены отдельные главы: теоретическое изучение медиа как междисциплинарной области и отечественные медиа как подсистема общества.

В первой главе последовательно рассматриваются общественные трансформации и медиа, выявляются основные тенденции развития общества, влияющие на СМИ, а также процессы, характерные для медиасистем. При этом уделено должное внимание внешним и внутренним факторам взаимовлияния, а также векторам их развития, что свидетельствует о тесной связи между изменениями общества и функционированием медиа. А это требует, по мнению автора, «ревизии» взглядов на СМИ, что служит основанием для междисциплинарности поля современных медиаисследований.

Современные медиа - достаточно сложное явление, которому присущи качества, требующие новых подходов в их изучении. Однако в отечественных исследованиях, как справедливо отмечает Е.Л.Вартанова, наблюдается «отсутствие широкого междисциплинарного видения исследований медиа, в том числе в контексте научного познания окружающего мира» (с. 20). В связи с этим представлен преимущественно используемый исследовательский инструментарий, количественный и качественный методы контент-анализа и приведена схема процесса изучения медиа (с. 24).

Логика исследования неизбежно приводит автора к ключевым понятиям тезауруса медиаисследований. Рассуждения, насыщенные анализом прошлого и оценкой современного состояния понятийного аппарата, позволяют автору сделать ряд примечательных выводов. К таким, на- пример, можно отнести утверждение, что «традиционная цепочка "пресса, радио, телевидение" меняется на новую "контент, канал, платформа“» (с. 44), а это влечет за собой дополнительные терминологические усовершенствования. Далее внимание автора сосредоточивается на определении понятия «медиа» и актуальных парадигмах исследований. В целом, что весьма важно, медиа рассматриваются как социальное пространство, как социальные институты и структуры, как социальные процессы. Также подчеркивается многоаспектность понятия «медиа» и выделяются их составные элементы: от институтов общества до технологических платформ. Следующее затем рассмотрение теоретических дискуссий свидетельствует о том, что термин «медиа» понимается еще достаточно широко, а следовательно, необходимо его дальнейшее уточнение. Несомненно заслуживают внимания и теоретические аспекты взаимодействия медиатехнологий и общества, в том числе модификация форматов медиапотребления и процесс цифровизации медиа и его влияние на современную жизнь общества.

Вопрос о факторах влияния на развитие медиаисследований в той или иной мере постоянно находится в поле зрения автора. Наряду с технологическими аспектами речь идет о двойственном характере теории медиа: универсальном и национальном, что весьма ощутимо в России. Оперируя примерами различнызх медийных теорий, автор справедливо прослеживает процесс их трансформации и подчеркивает сложность универсализации понятий, в том числе «медиа».

Вторая глава монографии посвящена отечественным медиа как подсистеме общества. Прежде всего в ней идет речь о теоретической актуальности концепции «медиасистема» и утверждается, что «в объектно-предметном поле медиа понятие "медиасистема " может стать впол- 
не адекватной единицей анализа» (с. 81). Она рассматривается многосторонне: как взаимосвязанный комплекс медиаканалов, медиаконтента, медиатехнологий, адресованных аудитории, действующих в рамках национального и международного законодательства, в контексте геополитического и экономического положения страны, ее этнокультурных условий и исторических традиций, а также особенностей идентичности аудитории (с. 87). При этом отмечается, что надо учитывать обновление подходов к определению и дополнительные факторы влияния, определяются рамки академического анализа отечественной медиасистемы и формулируется ее трансформация.

Другим важным вопросом в современном дискурсе являются теоретические подходы к рассмотрению медиаиндустрии в контексте медиасистемы. Этот весьма актуальный, но сложный, а порой запутанный вопрос также нашел отражение на страницах монографии. В ней уделено внимание понятию "медиаиндустрия» и его использованию, а также модернизации теоретических подходов к медиаиндустрии. Акцентируя внимание на развитии отрасли и усилении социальных эффектов СМИ в России, автор подчеркивает, что это ведет к «интенсификации взаимоотношений СМИ и различных социальных институтов, агентов, социальных групп» (с. 136). Именно поэтому возникает ощутимая потребность в формировании новых теоретических моделей СМИ и теоретического понимаяния медиаиндустрии. Как следствие, в академическом дискурсе все чаще поднимается вопрос о медиаполитике и медиарегулировании. С этим связан также вопрос о понятии обратной связи в концептуализации актуального взаимодействия аудитории и медиа. Эти и другие вопросы подчеркивают, что понимание журналистики в теории медиа не утрачивает своей актуальности. Больше того, по мнению автора, задача исследователей «не только предвидеть будущее» журналистики в теории, но и «приблизить его». А этому могут помочь такие векторы, как «общественная поддержка экономики журналистики, активное движение в сторону актуальных тем и технологий создания журналистских материалов, новое видение профессии, которое должно найти прочное место в журналистском образовании, научно фундированном теорией медиа» (с. 169). Заключает главу рассмотрение концептуальных основ медиаобразования и его принципов. В связи с этим подчеркивается, что «медиаграмотный человек должен демонстрировать владение двумя типами навыков: технологическими и информационно-аналитическими» (с. 177). Как показывает практика, навыки технологические осваиваются значительно легче, чем информационно-аналитические. А это порождает немало проблем и теоретического, и практического характера.

В целом, монография Е.Л. Вартановой свидетельствует о том, что теория медиа обретает свою ощутимую форму, что она выведена на новый уровень и что медиаисследования получают достаточно прочную теоретическую основу. Это «живая» теория, в которой внимание фокусируется на взаимосвязанном развитии общества и медиа, что определяет ее подвижность. В связи с этим можно предположить ее дальнейшее углубление и обогащение, а также усиление ее роли в научном дискурсе. Это основательный фундамент для понимания и изучения медиа и медиасистем в междисциплинарном поле исследований, о чем свидетельствуют результаты медиаисследований, проведенных весьма перспективным научным коллективом.

Учитывая возрастающую роль медиа в современном обществе и их трансформацию, теоретическое осмысление процессов будет приобретать все большее значение и расширять дискуссионные границы. 
В силу этого потребуются дальнейшие ша- медиа. Нет сомнений в том, что все это ги в освоении и развитии научной мыс- найдет отражение в теоретических трули, направленной на понимание и обоб- дах Е.Л. Вартановой и научного коллекщение природы, деятельности и развития тива ее кафедры.

\section{Примечания}

1 Грант РНФ № 17-18-01408.

2 Здесь и далее книга Е.Л. Вартановой «Теория медиа: отечественный дискурс» цитируется с указанием страницы в круглых скобках.

\section{Библиография}

Отечественная теория медиа: основные понятия. Словарь / под ред. Е.Л. Вартановой. М.: Фак. журн. МГУ; Изд-во Моск. ун-та, 2019.

От теории журналистики к теории медиа, Динамика медиаисследований в современной России / под ред. Е.Л. Вартановой. М.: Изд-во Моск. ун-та, 2019.

Трансформация отечественной теории медиа: состояние и тенденции развития / под ред. Е.Л. Вартановой. М.: МедиаМир, 2017.

Фундаментальные основы теории медиа в контексте общественного развития: опыт разработки / под ред. Е.Л. Вартановой. М.: Фак. журн. МГУ, 2019. 